\title{
The Algorithm for Precision Medicine (Invited Talk)
}

\author{
Matthew Might \\ University of Alabama at Birmingham \\ USA \\ might@cs.utah.edu
}

\begin{abstract}
Precision medicine promises to deliver ultra-personalized care by casting medicine as an optimization problem: identifying the best possible treatment with respect to all available data. A slew of recent advances in biology, starting with the ability to sequence the human genome, have caused an explosion in the amount of data one can collect on a single patient and a similar explosion in the complexity of reasoning about this data in order to solve this optimization problem. Computational support for the practicing physician is no longer an option. This talk covers precision medicine from the ground up for computer scientists - through a personal journey from programming languages research into academic medicine. It will demonstrate progress to date, including the now-routine use of relational programming in miniKanren to identify personalized treatments for patients with some of the rarest and most challenging diseases in the world.
\end{abstract}

\section{ACM Reference Format:}

Matthew Might. 2019. The Algorithm for Precision Medicine (Invited Talk). In Proceedings of the 2019 ACM SIGPLAN International Conference on Systems, Programming, Languages, and Applications: Software for Humanity (SPLASH Companion '19), October 20-25, 2019, Athens, Greece. ACM, New York, NY, USA, 1 page. https: //doi.org/10.1145/3359061.3365208

\section{Biography}

Matthew Might has been the Director of the Hugh Kaul Precision Medicine Institute at the University of Alabama at Birmingham (UAB) since 2017. At UAB, Matt is the Hugh Kaul Kaul Endowed Chair of Personalized Medicine, a Professor of Internal Medicine, and a Professor of Computer Science.

From 2016 to 2018, Matt was a Strategist in the Executive Office of the President in The White House. And, in 2015, Matt joined the faculty of the Department of Biomedical Informatics at the Harvard Medical School.

Matt is co-founder and Chief Scientific Officer of NGLY1.org, and he was a co-founder and Scientific Advisor to Pairnomix. Q State Biosciences acquired Pairnomix in October 2018 and Matt remains a Scientific Advisor.

Permission to make digital or hard copies of part or all of this work for personal or classroom use is granted without fee provided that copies are not made or distributed for profit or commercial advantage and that copies bear this notice and the full citation on the first page. Copyrights for thirdparty components of this work must be honored. For all other uses, contact the owner/author(s).

SPLASH Companion '19, October 20-25, 2019, Athens, Greece

(c) 2019 Copyright held by the owner/author(s).

ACM ISBN 978-1-4503-6992-3/19/10.

https://doi.org/10.1145/3359061.3365208 